\title{
Adjuvant radiotherapy treatment for soft tissue sarcoma of extremities and trunk. A retrospective mono-institutional analysis
}

\author{
R. SPOTO ${ }^{1,2, *}$, A. VAVASSORI ${ }^{1, *}$, S. DICUONZO ${ }^{1}$, M. PEPA $^{1}$, S. VOLPE ${ }^{1, *}$, O. ALESSANDRO ${ }^{1,2}$, S. GANDINI ${ }^{3}$, B. DI VENOSA ${ }^{4}$, E. MIGLIETTA ${ }^{1}$, \\ C. FODOR ${ }^{1}$, G. M. ORSOLINI ${ }^{5}$, P. PRESTIANNI ${ }^{5}$, F. CATTANI ${ }^{6}$, S. COMI ${ }^{6}$, R. LAZZARI ${ }^{1}$, G. RENNE ${ }^{4}$, T. DE PAS ${ }^{7}$, R. ORECCHIA ${ }^{8}$, E. PENNACCHIOLI ${ }^{5}$, \\ B. A. JERECZEK-FOSSA ${ }^{1,2}$
}

\begin{abstract}
${ }^{1}$ Division of Radiation Oncology, IEO, European Institute of Oncology IRCCS, Milan, Italy; ${ }^{2}$ Department of Oncology and Hemato-Oncology, University of Milan, Milan, Italy; ${ }^{3}$ Molecular and Pharmaco-Epidemiology Unit, Department of Experimental Oncology, IEO, European Institute of Oncology IRCCS, Milan, Italy; ${ }^{4}$ Division of Pathology and Laboratory Medicine, IEO, European Institute of Oncology IRCCS, Milan, Italy; ${ }^{5}$ Program of Melanoma, Sarcoma and Rare Tumors, IEO, European Institute of Oncology IRCCS, Milan, Italy; ${ }^{6}$ Unit of Medical Physics, European Institute of Oncology IRCCS, Milan, Italy; ${ }^{7}$ Department of Oncology, IEO, European Institute of Oncology IRCCS, Milan, Italy; ${ }^{8}$ Scientific Directorate, IEO, European Institute of Oncology IRCCS, Milan, Italy
\end{abstract}

${ }^{*}$ Correspondence: stefania.volpe@ieo.it

"Contributed equally to this work.

Received March 25, 2020 / Accepted June 5, 2020

\begin{abstract}
Soft tissue sarcomas (STS) are uncommon, heterogeneous malignant tumors of mesodermal origin. Other than conservative surgery (CS), neoadjuvant or adjuvant radiotherapy (RT) is recommended when the risk of local recurrence is high. The aim of this study is to present our Institutional experience in adjuvant RT for treatment of STS of extremities and trunk (with either brachytherapy (BRT), external beam RT (EBRT), or both) and to provide an insight of toxicity and oncological outcomes for each RT modality. According to the RT treatment approach, patients were divided into three categories: 1) BRT alone; 2) EBRT alone; 3) combined BRT+EBRT. Differences among the three groups were assessed by the Chi-squared test. Patients' follow-up was performed every 6 months for the first two years after the end of RT and then once a year. Data from 90 patients were analyzed. The overall 3-year distant relapse-free survival (DRFS), progression-free survival (PFS), and overall survival (OS) were $84 \%, 80 \%$, and $97 \%$, respectively. Acute erythema was the most frequent side effect, although severe grade 3 toxicity was present in 5 patients. Chronic toxicity of any grade was reported in 14 patients. The incidence of chronic toxicity did not show any association with treatment modality. Multivariate analysis suggested a significant correlation between acute toxicity and tumor size, RT modality, and RT dose. In conclusion, good local control and toxicity profile were observed, despite negative patients' selection at baseline. Further investigation on wider series is warranted in order to define the optimal combination with systemic therapy.
\end{abstract}

Key words: sarcoma, brachytherapy, external beam radiotherapy

Soft tissue sarcoma (STS) is an uncommon, extremely heterogeneous group of malignant tumors of mesodermal origin $[1,2]$. More than half of patients develop STS in extremities and trunk. Nowadays, conservative surgery represents a well-established treatment for STS of both extremities and trunk. National and international guidelines $[1,3]$ recommend an 'en bloc' wide resection of the lesion with negative margins, performed by an experienced surgeon, based on a prior decision of a multidisciplinary board. Radiotherapy (RT) represents the complementary treatment modality of choice STS deemed as at high risk of local recurrence (LR), including stage IIA-III, per the Union for International Cancer Control (UICC) tumor-nodes-metastasis (TNM) 2009 classification [4].
Nevertheless, no full consensus exists on the exact timing of RT. Neoadjuvant versus adjuvant setting was evaluated in a randomized trial [5] in terms of acute wound complications (4 months after the end of RT) and LR. Although available data suggest a comparable rate of LR, pre-operative RT has been associated with a higher risk of wound complications, while post-operative RT seems to yield more long-term functional impairment, which is probably related to higher doses and wider irradiation fields [6-9]. Another source of variability in the post-operative setting is the absence of a gross tumor volume; therefore, the positioning of radiopaque clips at the moment of surgery is of paramount importance.

Different RT techniques (namely, interstitial brachytherapy-BRT, three dimensional conformal RT-3D-CRT, 
intensity-modulated RT-IMRT, and intraoperative RT-IORT) have shown similar oncological outcomes which can be used in combination according to specific patients' anatomy and single-center expertise.

The aim of the current report is to present our Institutional experience in the treatment of STS of extremities and trunk treated after surgery with either BRT, EBRT or a combination of both, and to provide an insight of toxicity and oncological outcomes for each RT modality.

\section{Patients and methods}

The inclusion criteria were as follows: 1) patients treated between November 1999 and September 2016; 2) non-metastatic STS of limbs and trunk; 3) RT performed as adjuvant treatment following radical wide excision surgery; 4) written informed consent for the treatment and for the use of anonymized clinical data for research and educational purposes.

Every patient's case was discussed at the weekly multidisciplinary tumor board, whose members included experienced dedicated surgeons, radiation oncologists, medical oncologists, and radiologists. Specifically, indication for RT considered the presence of well-recognized tumor-related risk factors: grading, tumor size, and depth. Additional factors such as proximity to critical structures were considered in determining the choice of the optimal RT technique. According to the RT treatment approach, patients were divided into three categories: 1) BRT alone; 2) EBRT alone; 3) combined BRT+EBRT.

Surgery. Surgery is the cornerstone of STS treatment. The aim of radical surgery is to obtain a wide negative resection margin by an 'en bloc' excision of the tumor mass compartment; biopsy scars and drainage sites should be included in the surgery field. For the purpose of our study, surgical margins were considered microscopically positive if the tumor was within $1 \mathrm{~mm}$ from the margin.

Brachytherapy. Indication to BRT was given at the moment of surgery following Radiation Oncologist's and Surgeon's joint evaluation. The first step was the feasibility assessment, in which the proximity of catheters to neurovascular structures was considered a major contraindication to BRT due to toxicity concerns. The second step consisted of the choice of performing BRT alone or combined with EBRT: favorable patient anatomy, small tumor volume, and negative resection margins were all criteria for the indication for BRT only. In the case the three criteria were not completely fulfilled, the patient underwent a combined treatment approach consisting of an anticipated BRT boost followed by EBRT. Also, microscopic tumor invasion of resection margins was considered as an exclusion criterion for BRT alone. For each patient, the tumor bed was identified in cooperation with the operating surgeon; the target area was then expanded by $2 \mathrm{~cm}$ margin in superior and inferior dimension and a $1.5-2 \mathrm{~cm}$ margin in the medial and lateral dimension.
Subsequently, the target area was implanted percutaneously with a single plane array of after-loading plastic catheters, placed percutaneously, spaced at approximately $1-1.5 \mathrm{~cm}$, perpendicularly to the resection axis. The catheters were then secured to the skin at the catheter exit site with buttons. The drainage was placed over the tumor bed, and the wound was closed in layers. The BRT implantation was performed according to the Paris system rules for BRT dosimetry [10]. The treatment was delivered in a pulse dose rate (PDR) or high dose rate (HDR) modality using an Iridium-192 source, remote after-loader. The median delivered dose for the BRT alone treatment modality was $45 \mathrm{~Gy}$, while it was $15 \mathrm{~Gy}$ in case BRT was used as an anticipated boost. For HDR-BRT treatment equivalent dose in $2 \mathrm{~Gy}$ fractions was calculated with the linear quadratic model with $\alpha / \beta=4$ Gy [11].

External beam radiotherapy. All patients treated with EBRT, alone or in combination with BRT, underwent a simulation-CT scan, with a $2.5 \mathrm{~mm}$ slice thickness. The tumor bed was delineated using the clips positioned at the moment of surgery as guidance; pre-surgery magnetic resonance imaging whenever available were reviewed for better anatomical delineation of the target region. Clinical target volume (CTV) was obtained by expanding from 3 to $5 \mathrm{~cm}$ the tumor bed in all directions, considering the proximity of bone, joint, and neurovascular structures. Finally, a margin of at least $1 \mathrm{~cm}$ was given in all directions to obtain the planning target volume (PTV).

Toxicity. Patients' follow-up was performed every 6 months for the first two years after the end of RT and then once a year, in some cases even by a phone call. Acute and chronic toxicities reported in the analysis represented the maximal recorded toxicities for the whole course of follow-up. The following descriptors of acute toxicity were retrieved: erythema, edema, pain, and wound complication; the latter were dichotomized as mild and severe. Infections and seromas which resolved after 2-3 aspirations were considered as a mild complication, while seromas requiring repeated aspirations and/or drainage or tissue-damaging leading to any surgical procedure were classified as severe complications. Atrophy, pain, edema, and fibrosis-related motor impairment were considered as late complications if occurred from 6 months to 3 years after surgery. Acute and late toxicity was graded according to the Common Terminology Criteria for Adverse Events (CTCAE 4.0) scoring system [12]. The pain was evaluated by the Numerical Rating Scale (NRS) score system $(0=$ no symptoms, $10=$ worst degree of symptoms) and furtherly categorized as absent (0), light (1-3), moderate $[10-13]$ or severe $[6,14,15]$.

Statistical analysis. Patients' and tumors' characteristics were classified as categorical variables in terms of both absolute frequencies and percentages. Median values and interquartile range were calculated for continuous variables. Differences among the three different groups (i.e. BRT only, EBRT only, and BRT followed by EBRT) were assessed by the Chi-squared test. 
Considered as starting from the operation date, all patients alive or disease-free at last follow-up were considered right-censored. Three-year local relapse-free survival (LRFS), distant relapse-free survival (DRFS), progressionfree survival (PFS)-considering both local and distant relapse, and overall survival (OS) curves were estimated by the Kaplan-Meier method. The log-rank test was used to identify prognostic factors and confounders significantly associated with survival curves and compare them for the three treatment groups. Chi-square tests (for categorical variables) and Wilcoxon rank-test (for continuous variables) were used to identify factors associated with acute toxicity. Multivariate logistic models were used to identify factors independently associated with acute toxicity and multivariate Cox hazard models were carried out to identify significant factors independently associated with LRFS, DRFS, PFS, and OS. Odd ratios (ORs) and corresponding 95\% Confidence intervals (CI) of factors significantly associated with acute toxicity in multivariate models are presented. All statistical tests were two-sided, and a p-value $<0.05$ was considered statistically significant. The statistical analyses were performed with the Statistical Analysis System, version 9.2 (SAS Institute, Cary, NC).

\section{Results}

Out of the one-hundred-thirty consecutive patients who were treated from November 1999 to September 2016 with surgery and adjuvant RT, ninety met the inclusion criteria. Two patients were excluded as they failed to complete RT due to severe wound complications of the surgical bed, thus leading to a final cohort of eighty-eight patients. Patients' characteristics are summarized in Table 1.

At the moment of the first consultation at our Institute, 31 (35\%) patients had not received any treatment for STS, while the majority of them $(51 \%)$ had undergone a previous inadequate surgery needing radicalization, and $12(14 \%)$ had LR. Tumor characteristics were not available when the patient was treated at first in another Institute. Tumor size was obtainable for $66 \%$ of patients: $36 \%$ of them $(n=32)$ were $>5 \mathrm{~cm}$ and $30 \%(\mathrm{n}=26)$ were $\leq 5 \mathrm{~cm}$. TNM 2009 and updated 2017 classification are listed in Table 2.

The histological grading was expressed in $86 \%$ of patients using the French Federation classification (FNCLCC) [13], while the tumor depth was available for $67 \%$ of patients (Table 1). The most frequent histology was liposarcoma (33\%), followed by leiomyosarcoma (14\%). For statistical purposes, we decided not to divide the liposarcoma into its 4 subtypes.

All patients underwent surgery at our Institute. Only in 5 cases (6\%), there was a microscopic tumor invasion of resection margins: this aspect excluded them from BRT alone group. After surgery, all patients were referred to RT treatment, performed in one of the three modalities: BRT alone $(n=20)$, EBRT alone $(n=26)$ or EBRT+BRT $(n=42)$.
BRT was delivered using PDR in 45 patients (73\%) (median dose rate $=0.5 \mathrm{~Gy} / \mathrm{h}$ ) and HDR in $17(17 \%)$ patients (median dose/fraction $=3.4 \mathrm{~Gy} /$ fraction). The median dose delivered for BRT alone was 45 Gy and 34 Gy to $95 \%$ of CTV for PDR and HDR treatment respectively, for EBRT alone was $59.4 \mathrm{~Gy}$ to $95 \%$ of PTV and for the combined treatment was 15 Gy-anticipated boost with BRT plus $45 \mathrm{~Gy}$ with EBRT.

Adjuvant chemotherapy was administrated in 10 patients (11\%) following RT. The combination of Epirubicin with Ifosfamide was the most commonly prescribed scheme.

The median follow-up was 4.2 years (range $0.2-16.7$ years). The analysis of the main tumor characteristics (Table 1) showed a significant lower frequency of G3 sarcomas (35\% vs. $58 \%$ in EBRT and $45 \%$ in BRT+EBRT groups; $\mathrm{p}=0.03$ ) and a prevalence of pT1 in BRT group (60\% vs. $38 \%$ and $28 \%$ in EBRT and EBRT+BRT, respectively; $\mathrm{p}=0.02$ ).

The overall 3-year LRFS was 91\% (90\% for Group 1, 92\% for Group 2 and 90\% for Group 3, p=0.96). We observed only 8 cases of LR as the first event after treatment: half of them had undergone a previous inadequate surgery elsewhere, while the remaining had received primary treatment at our institution (Table 3).

The overall 3-year DRFS was $84 \%$, with a significant difference between groups: $100 \%$ in BRT, $88 \%$ in EBRT, and $74 \%$ in the BRT+EBRT group (Table $4, \mathrm{p}=0.02$ ). The overall actuarial 3-year PFS was $80 \%$ (Figure 1A). PFS curves by groups (Figure 1B) showed the tendency of the combined treatment $(\mathrm{BRT}+\mathrm{RT})$ to have a worse prognosis, but the differences were not statistically significant $(\mathrm{p}=0.11)$.

The three-year actuarial OS rate was $97 \%$ (Figure 1C). No statistically significant difference was found for OS among the three groups ( $\mathrm{p}=0.92$, Table 4$)$, with 5 total deaths, of which 3 without the disease. None of the other demographic, tumor, and clinical characteristics were significantly associated with PFS and OS in univariate nor multivariate analyses.

Regarding the analysis of acute skin toxicity (Table 5), erythema was the most frequent side effect, although severe Grade 3 toxicity was present in 5 patients ( 1 in EBRT and 4 in the BRT+EBRT group). Only Grade 2 edema was observed in $16 \%(\mathrm{n}=14)$ patients. At the end of the RT, $17 \%$ of patients $(n=12)$ reported some grade of pain: 7 light $(\mathrm{NRS} \leq 3)$ and 5 moderated pain. Mild and severe wound complications were reported in $7(8 \%)$ and $6(7 \%)$ patients, respectively.

Chronic toxicity (Table 5) was registered within 3 years from surgery and was available for 77 (85\%) patients. Chronic toxicity of any grade was reported by 14 patients, and presented as follows: motor impairment in 8 patients $(1,4$, and 3 patients in BRT, EBRT, and BRT+EBRT groups, respectively), chronic edema in 4 , chronic moderate pain in 2 , and atrophy in 2 . The incidence of chronic toxicity did not show any association with treatment modality in the present cohort.

Univariate analysis showed a significant association between RT modality and acute skin toxicity, which was significantly more frequent in the EBRT arm, $\mathrm{p}=0.002$ ). 
Table 1. Patient-, tumor- and treatment- related characteristics.

\begin{tabular}{|c|c|c|c|c|c|}
\hline Variable & Overall & BRT & EBRT & BRT+EBRT & p-value \\
\hline Patients, n (\%) & $88(100)$ & $20(22)$ & $26(30)$ & $42(48)$ & \\
\hline \multicolumn{6}{|c|}{ Age (years) - median 53; range $15-86$} \\
\hline$\leq 60, \mathrm{n}(\%)$ & $52(59)$ & $11(55)$ & $15(58)$ & $26(62)$ & \multirow{2}{*}{0.86} \\
\hline$>60, \mathrm{n}(\%)$ & $36(40)$ & $9(45)$ & $11(42)$ & $16(38)$ & \\
\hline \multicolumn{6}{|l|}{ Sex, n (\%) } \\
\hline Male & $50(57)$ & $12(60)$ & $15(58)$ & $23(55)$ & \multirow{2}{*}{0.92} \\
\hline Female & $38(43)$ & $8(40)$ & $11(42)$ & $19(45)$ & \\
\hline \multicolumn{6}{|l|}{ Grade (G), n (\%) } \\
\hline Low (G1) & $18(20)$ & $3(15)$ & $7(27)$ & $8(19)$ & \multirow{4}{*}{0.03} \\
\hline Intermediate (G2) & $17(19)$ & $9(45)$ & $1(4)$ & $7(17)$ & \\
\hline High (G3) & $41(47)$ & $7(35)$ & $15(58)$ & $19(45)$ & \\
\hline Missing & $12(14)$ & $1(5)$ & $3(12)$ & $8(19)$ & \\
\hline \multicolumn{6}{|l|}{$\mathrm{pT}, \mathrm{n}(\%)$} \\
\hline $\mathrm{T} 1$ & $34(38)$ & $12(60)$ & $10(38)$ & $12(28)$ & \multirow{3}{*}{0.02} \\
\hline $\mathrm{T} 2$ & $48(55)$ & $5(25)$ & $15(58)$ & $28(67)$ & \\
\hline Missing & $6(7)$ & $3(15)$ & $1(4)$ & $2(5)$ & \\
\hline \multicolumn{6}{|l|}{ Site, $\mathrm{n}(\%)$} \\
\hline Upper limb & $16(18)$ & $3(15)$ & $6(23)$ & $7(17)$ & \multirow{3}{*}{0.29} \\
\hline Lower limb & $62(71)$ & $14(70)$ & $20(77)$ & $28(66)$ & \\
\hline Trunk & $10(11)$ & $3(15)$ & $0(0)$ & $7(17)$ & \\
\hline \multicolumn{6}{|c|}{ Size $(\mathrm{cm})$ - median 5.7; range 3.1-9.8 } \\
\hline$>5, \mathrm{n}(\%)$ & $32(36)$ & $4(20)$ & $10(38)$ & $18(43)$ & \multirow{3}{*}{0.20} \\
\hline$\leq 5, \mathrm{n}(\%)$ & $26(30)$ & $9(45)$ & $9(35)$ & $8(19)$ & \\
\hline Missing, n (\%) & $30(34)$ & $7(35)$ & $7(27)$ & $16(38)$ & \\
\hline \multicolumn{6}{|l|}{ Depth, n (\%) } \\
\hline Superficial & $11(13)$ & $4(20)$ & $4(15)$ & $3(7)$ & \multirow{3}{*}{0.27} \\
\hline Deep & $48(54)$ & $9(45)$ & $17(66)$ & $22(52)$ & \\
\hline Missing & $29(33)$ & $7(35)$ & $5(19)$ & $16(38)$ & \\
\hline \multicolumn{6}{|l|}{ Reason for surgery, n (\%) } \\
\hline Primary & $31(35)$ & $5(25)$ & $11(42)$ & $15(36)$ & \multirow{3}{*}{0.20} \\
\hline Recurrent & $12(14)$ & $3(15)$ & $6(23)$ & $3(7)$ & \\
\hline Radicalization & $45(51)$ & $12(60)$ & $9(35)$ & $24(57)$ & \\
\hline \multicolumn{6}{|l|}{ Microscopic margin, n (\%) } \\
\hline Positive & $5(6)$ & $0(0)$ & $3(12)$ & $2(5)$ & \multirow{2}{*}{0.23} \\
\hline Negative & $83(94)$ & $20(100)$ & $23(88)$ & $40(95)$ & \\
\hline \multicolumn{6}{|c|}{ Postoperative chemotherapy, n (\%) } \\
\hline Yes & $10(11)$ & $1(5)$ & $4(15)$ & $5(12)$ & \multirow{2}{*}{0.53} \\
\hline No & $78(89)$ & $19(95)$ & $22(85)$ & $37(88)$ & \\
\hline \multicolumn{6}{|l|}{ Histopathology, n (\%) } \\
\hline Liposarcoma & $29(33)$ & $4(20)$ & $9(34)$ & $16(38)$ & \multirow{6}{*}{0.75} \\
\hline Leiomyosarcoma & $12(14)$ & $4(20)$ & $5(19)$ & $3(7)$ & \\
\hline Pleomorphic sarcoma & $7(8)$ & $3(15)$ & $2(8)$ & $2(5)$ & \\
\hline Synovial sarcoma & $3(3)$ & $0(0)$ & $1(4)$ & $2(5)$ & \\
\hline MPNST & $3(3)$ & $1(5)$ & $1(4)$ & $1(2)$ & \\
\hline Other & $34(39)$ & $8(40)$ & $8(31)$ & $18(43)$ & \\
\hline Type of BRT, n (\%) & $62(70)$ & $20(100)$ & 0 & $42(100)$ & \\
\hline HDR & $17(27)$ & $7(35)$ & - & $10(24)$ & 035 \\
\hline PDR & $45(73)$ & $13(65)$ & - & $32(76)$ & $0 . J 3$ \\
\hline
\end{tabular}

Abbreviations: $\mathrm{n}$ - number; MPNST - malignant peripheral nerve sheath tumors; HDR - high dose rate; PDR - pulse dose rate. Significant p-values in bold. ${ }^{*}$ Chi-squared test 
Conversely, we could not identify any statistically significant correlation between chronic toxicity and RT modality for none of the analyzed RT combinations ( $\mathrm{p}=0.25$, Figure 2 ).

Multivariate analysis (Table 6) confirmed a significant association between acute toxicity and RT modality, dose, and tumor size: acute toxicity is significantly associated with EBRT ( $\mathrm{p}=0.008)$, with RT dose $(\mathrm{p}=0.001)$ and with size $>5 \mathrm{~cm}(\mathrm{p}=0.031)$. All other risk factors, tumor, were resulted not statistically significant (data not shown).

\section{Discussion}

In this retrospective study, we analyzed the oncological and toxicity outcomes of the adjuvant RT treatment of limbs and trunk STS from 1999 to 2016 at our institution. Our research showed high local control rates after a combined therapy (surgery and radiation) and a favorable toxicity profile.

All the adjuvant treatment subgroups included in the analysis (BRT alone, EBRT alone, BRT+EBRT) were treated in compliance with national guidelines [1].

Table 2. Disease staging according to AJCC TNM 2009 and AJCC TNM 2017 classifications-comparison.

\begin{tabular}{lcc}
\hline TNM & $\mathbf{2 0 0 9}$ & $\mathbf{2 0 1 7}$ \\
\hline I (a-b) & $15(4-11)$ & $15(4-11)$ \\
II (a-b) & $30(24-6)$ & 23 \\
III (a-b) & 15 & $22(12-10)$ \\
Missing, $\mathbf{n}$ & 28 & 28 \\
\hline
\end{tabular}

Abbreviations: AJCC-TNM - American Joint Committee on Cancer-

Tumor, Nodes, Metastases
While the role of adjuvant RT after limb-sparing surgery in high-grade STS is well-recognized [14], the optimal timing is still to be defined. The adjuvant and the neoadjuvant approaches have been compared in a randomized clinical trial by O'Sullivan et al., whose results showed that parameters such as tumor size and location should be considered at the moment of clinical indication [6]. No further clarification can be derived from currently available national guidelines, specifically regarding the optimal timing and modality of adjuvant treatment is provided $[1,15]$.

One retrospective multi-institutional analysis [16] comparing EBRT in adjuvant vs. neoadjuvant setting in 821 patients, showed a trend towards a reduction in cancerspecific mortality for the neoadjuvant cohort.

Moreover, it should be considered that surgery modality (i.e. inappropriate/incomplete surgery) and clinical history (i.e. never treated before, disease relapse) act as independent prognostic factors regardless of the treatment modality of choice [17].

The analysis of the main prognostic factors [18], sorted by treatment groups, highlighted a tendency towards a possible positive selection of candidates to the BRT-only arm. This was not surprising, as in current clinical practice BRT is used as an exclusive treatment in patients with low grade, small size sarcomas, for which it was deemed possible to fully encompass the surgical bed [19].

The American Brachytherapy Society consensus statement for sarcoma BRT [20] reviewed in 2017 the different BRT modalities (Low Dose Rate-LDR, HDR, and PDR) and the possible association with EBRT, concluding that LDR, HDR, and PDR can all be considered as valid alternatives. In our Institute, BRT was delivered with PDR in 45 patients,

Table 3. Histological characteristics of patients with local recurrence.

\begin{tabular}{llccc}
\hline Patient & Histology & Grading & Margins & T diameter \\
\hline P1 & Spindle cell sarcoma & R2 & 10 \\
P2 & Mixofibrosarcoma & G2, focally G3 & R0 & 7 \\
P3 & Leiomyosarcoma & G3 & R0 & 6.5 \\
P4 & Malignant histiocytoma & N.A. & N.A. & N.A. \\
P5 & Liposarcoma & G3 & N.A. & 10 \\
P6 & NAS sarcoma, with myxoid features & G3 & R0 & N.A. \\
P7 & Pleomorphic sarcoma & G3 & R0 & N.A. \\
P8 & Pleomorphic liposarcoma & G3 & R0 & N.A. \\
\hline
\end{tabular}

Abbreviations: NA - not available; NOS - not otherwise specified; R0 - negative surgical margin; R1 - positive surgical margins; $\mathrm{P}=$ patient. ${ }^{*}$ Tumor diameter on surgical specimen. ${ }^{*}$ Extended to 1 of the lateral margins.

Table 4. Oncological outcomes of interest as sorted per treated modality.

\begin{tabular}{lccccc}
\hline Outcome (\%) & Overall $(\mathbf{n}=\mathbf{8 8})$ & BRT $(\mathbf{n}=\mathbf{2 0})$ & EBRT $(\mathbf{n}=\mathbf{2 6})$ & BRT+EBRT $(\mathbf{n}=\mathbf{4 2})$ & $\mathbf{p}$-value \\
\hline LRFS & 91 & 90 & 92 & 90 & 0.96 \\
DRFS & 84 & 100 & 88 & 74 & $\mathbf{0 . 0 2}$ \\
OS & 94 & 95 & 96 & 93 & 0.84 \\
\hline
\end{tabular}

Abbreviations: $\mathrm{n}$ - number; BRT - brachytherapy; EBRT - external beam radiotherapy; LRFS - local relapse-free survival (actuarial rates of patients free of local relapse at three years); DRFS - distant relapse-free survival (actuarial rates of patients free of distant relapse at three years); OS - overall survival; Significant $\mathrm{p}$-values are in bold. ${ }^{*}$ Log-rank test. 

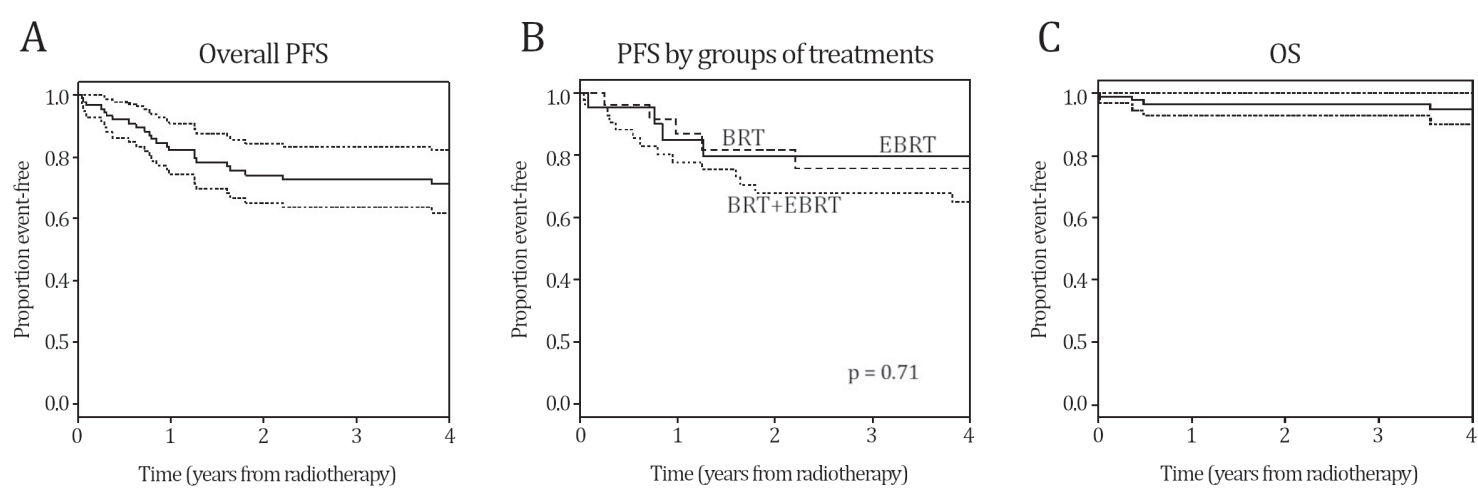

Figure 1. A) Overall progression-free survival; B) Analyses of progression-free survival curves by groups of treatment; C) Overall survival; abbreviations: BRT - brachytherapy; EBRT - external beam radiotherapy; PFS - progression-free survival; OS - overall survival

Table 5. Acute and chronic toxicities as sorted per treated modality.

\begin{tabular}{|c|c|c|c|c|}
\hline Level & Total $(n=88)$ & BRT $(n=20)$ & EBRT $(n=26)$ & BRT+EBRT $(n=42)$ \\
\hline \multicolumn{5}{|l|}{ Acute toxicity } \\
\hline \multicolumn{5}{|c|}{ All (any grade), n (\%) } \\
\hline No & $34(39)$ & $13(65)$ & $3(12)$ & $18(43)$ \\
\hline Yes & $54(61)$ & $7(35)$ & $23(88)$ & $24(57)$ \\
\hline \multicolumn{5}{|c|}{ Erythema, n (\%) } \\
\hline G0 & $37(42)$ & $14(70)$ & $3(12)$ & $20(48)$ \\
\hline G1 & $28(32)$ & $6(30)$ & $14(54)$ & $8(19)$ \\
\hline G2 & $18(20)$ & $0(0)$ & $8(30)$ & $10(24)$ \\
\hline G3 & $5(6)$ & $0(0)$ & $1(4)$ & $4(9)$ \\
\hline Any grade & $51(58)$ & $6(30)$ & $23(88)$ & $22(52)$ \\
\hline \multicolumn{5}{|l|}{ Edema, n (\%) } \\
\hline G0 & $74(84)$ & $17(85)$ & $17(65)$ & $37(88)$ \\
\hline G2 & $14(16)$ & $3(15)$ & $6(35)$ & $5(12)$ \\
\hline \multicolumn{5}{|c|}{ Pain (NRS), n (\%) } \\
\hline 0 & $76(86)$ & $19(95)$ & $20(77)$ & $37(88)$ \\
\hline$\leq 3$ & $7(8)$ & $0(0)$ & $4(15)$ & $3(7)$ \\
\hline$(3-7)$ & $5(6)$ & $1(5)$ & $2(8)$ & $2(5)$ \\
\hline \multicolumn{5}{|c|}{ Wound complications, n (\%) } \\
\hline No & $75(85)$ & $17(85)$ & $22(84)$ & $36(86)$ \\
\hline Mild & $7(8)$ & $2(10)$ & $2(8)$ & $3(7)$ \\
\hline \multirow[t]{2}{*}{ Severe } & $6(7)$ & $1(5)$ & $2(8)$ & $3(7)$ \\
\hline & $\mathrm{n}=75$ & $n=19$ & $\mathrm{n}=21$ & $\mathbf{n}=35$ \\
\hline \multicolumn{5}{|c|}{ Chronic toxicity } \\
\hline \multicolumn{5}{|c|}{ All (any grade), n (\%) } \\
\hline No & $61(69)$ & $15(75)$ & $15(57)$ & $31(74)$ \\
\hline Yes & $14(16)$ & $4(20)$ & $6(23)$ & $4(9)$ \\
\hline Missing & $13(15)$ & $1(5)$ & $5(20)$ & $7(17)$ \\
\hline \multicolumn{5}{|l|}{ Atrophy, n (\%) } \\
\hline Yes & $2(3)$ & $1(5)$ & $1(5)$ & 0 \\
\hline \multicolumn{5}{|c|}{ Motor impairment, n (\%) } \\
\hline Yes & $8(11)$ & $1(5)$ & $4(19)$ & $3(9)$ \\
\hline \multicolumn{5}{|c|}{ Pain (NRS), n (\%) } \\
\hline$\leq 3$ & $1(1)$ & $1(5)$ & 0 & 0 \\
\hline$(3-7)$ & $2(3)$ & $1(5)$ & 0 & 0 \\
\hline \multicolumn{5}{|l|}{ Edema, n (\%) } \\
\hline Yes & $4(5)$ & 0 & $3(14)$ & $1(3)$ \\
\hline
\end{tabular}

Abbreviations: NRS - Numeric Rating Scale (from 0 to 10); n - number of patients; BRT -brachytherapy; EBRT - external beam radiotherapy 
representing $73 \%$ of the overall BRT treatment. Previous institutional experience on PDR-BRT has shown that such treatment modality is safe, effective, and well-tolerated in patients with STS [21].

We found a 3 -year actuarial OS of $97 \%$, with no significant difference among the three treatment groups. Our data favorably compare with those published by Nesseler et al. in a recent retrospective study [22], in which the 5-year actuarial OS was $90.4 \%$ with an overall 3-years LRSF of $91 \%$. A similar rate of LRFS was documented in a retrospective study of the University of Copenhagen Hospital, Denmark [23] in a cohort of 39 patients treated with surgery followed by PDR-BRT+EBRT.

We report a statistically significant DRFS, but this result is possibly due to a selection bias in the BRT-only arm, as previously discussed, and is comparable to another retrospective analysis that studied the combined treatment modality [24]. The actuarial 3-year PFS rate in our study was $80 \%$. The worse PFS trend of the EBRT+BRT group could be explained by the higher proportion of distant metastases (11 patients, 26\%), possibly due to the higher presence of biologically aggressive tumors ( $\mathrm{n}=19$, grade 3 tumor).

Wound complications of any grade were recorded in 13 (15\%) cases, which is line with data from the randomized trial of the National Cancer Institute of Canada [6], where the rate of wound complication was reported to be $17 \%$.

Chronic toxicity at 2 years could be assessed on 75 (85\%) patients; of those 14 reported muscle weakness, edema, and/or pain of mild entity. Although, most patients declare no symptoms or any other side effects since the last early follow-up.

In the randomized trial of the Princess Margaret Hospital, Toronto, Canada [25], the incidence of edema and joint stiffness was $23.2 \%$. When comparing this data with our findings, it should be noted that retrospective collections typically underestimate the incidence of chronic events, due to the lack of homogenous follow-up data and to physician underreporting of mild, chronic toxicities.

The major limitations of our study lie in its retrospective nature and relatively small sample size, especially when the sub-cohorts of patients undergoing different treatments are considered individually.

Despite some data were missing (i.e. tumor size, grading, chronic toxicity assessment) we still could confirm that all the three RT treatment modalities (BRT, EBRT, BRT followed by EBRT) provide the same clinical outcomes without any clear difference in the tolerability profile in terms of both acute and chronic toxicity. As for regards patients' stratification, we observed that BRT alone could be regarded as the first treatment option in patients with small tumors, with a lower incidence of acute events as compared to 3D-CRT alone.

Nowadays, the progressive introduction of IMRT, in both adjuvant and neoadjuvant settings, seems to provide better local control compared to BRT [26], despite results from randomized clinical trials are awaited. Furthermore, thanks

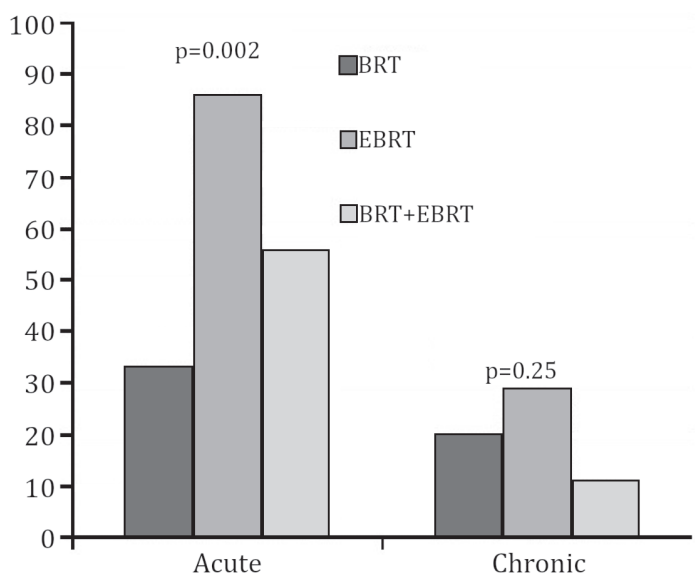

Figure 2. Univariate analyses of acute and chronic toxicity by groups of treatment. Abbreviations: BRT - brachytherapy; EBRT - external beam radiotherapy

Table 6. Multivariate analysis correlating acute toxicity and type of radiotherapy, dose and tumor size.

\begin{tabular}{lcc}
\hline Risk factor & OR $(\mathbf{9 5} \%$ CI $)$ & p-value \\
\hline Type of radiotherapy & & \\
EBRT vs. BRT & $10.9(1.7-69.9)$ & $\mathbf{0 . 0 0 8}$ \\
EBRT+BRT vs. BRT & $1.29(0.35-4.69)$ & 0.132 \\
Dose $(\mathrm{Gy})^{\mathrm{a}}$ & $1.07(1.03-1.11)$ & $\mathbf{0 . 0 0 1}$ \\
Size $(\mathrm{cm})$ & & \\
$>5$ vs. $\leq 5$ & $6.55(1.31-32.7)$ & $\mathbf{0 . 0 3 1}$ \\
$\quad$ Missing vs. $\leq 5$ & $2.08(0.56-7.75)$ & 0.716 \\
\hline
\end{tabular}

Abbreviations: OR - Odds Ratio; CI - confidence interval; BRT - brachytherapy; EBRT - external beam radiotherapy. ${ }^{\mathrm{a} F o r}$ HDR-BRT treatment equivalent dose $2 \mathrm{~Gy}$ was calculated with the linear quadratic model with $\alpha / \beta=4$ Gy. Significant p-values are in bold.

to the possibility of achieving better dose conformality, IMRT is expected to lower the toxicity rate of $3 \mathrm{D}$-CRT. This hypothesis is currently supported by two retrospective works, showing a reduction in the observed risk of femoral fracture [27] and wound-related morbidities [28]. Furthermore, two recently-published series have shown that volumetric arc therapy (VMAT) is an alternative promising technique [29, 30] with one work showing its ability to outperform IMRT in sparing dose to normal-tissue-corridor and, subsequently, the risk of lymphedema [30].

In conclusion, our series of 88 patients, treated with wide surgical excision followed by RT $(\mathrm{EBRT} \pm \mathrm{BRT})$ for extremities and trunk STS, showed a high local control and good toxicity profile despite negative patients' selection at baseline (recurrent disease, high-grade cases, etc.). The main pattern of failure was a metastatic progression, in particular for high-grade tumors. Further investigation on wider series is warranted in order to define the optimal combination with systemic therapy. 
Acknowledgments: This work was partially supported by Fondazione IEO-CCM, by a research grant from Accuray Inc. and by the Italian Ministry of Health with Ricerca Corrente and 5x1000 funds. The sponsors did not play any role in the study design, collection, analysis, and interpretation of data, nor in the writing of the manuscript, nor in the decision to submit the manuscript for publication. This study was partially supported by the Italian Ministry of Health with "Progetto di Eccellenza". Stefania Volpe is a $\mathrm{PhD}$ student within the European School of Molecular Medicine (SEMM).

\section{References}

[1] NATIONAL COMPREHENSIVE CANCER NETWORK. NCCN Clinical Practice Guidelines in Oncology (NCCN Guidelines)- Soft Tissues Sarcoma Version 2.2020- 28 May 2020. https://www.nccn.org/professionals/physician_gls/ $\mathrm{PDF} /$ sarcoma.pdf

[2] BOURCIER K, LE CESNE A, TSELIKAS L, ADAM J, MIR $\mathrm{O}$ et al. Basic Knowledge in Soft Tissue Sarcoma. Cardiovasc Intervent Radiol 2019; 42: 1255-1261. https://doi. org/10.1007/s00270-019-02259-w

[3] CASALI PG, ABECASSIS N, ARO HT, BAUER S, BIAGINI $\mathrm{R}$ et al. Soft tissue and visceral sarcomas: ESMO-EURACAN Clinical Practice Guidelines for diagnosis, treatment and follow-up. Ann Oncol 2018; 29: iv51-iv67. https://doi. org/10.1093/annonc/mdy096

[4] SOBIN LH, GOSPODAROWICZ MK, WITTEKIND C. (Eds.). TNM Classification of Malignant Tumours, 7th Edition. New York, Wiley-Blackwell; 2010, pp 310. ISBN 978-14443-3241-4

[5] DAVIS AM, O'SULLIVAN B, BELL RS, TURCOTTE R, CATTON CN et al. Function and Health Status Outcomes in a Randomized Trial Comparing Preoperative and Postoperative Radiotherapy in Extremity Soft Tissue Sarcoma. J Clin Oncol 2002; 20: 4472-4477. https://doi.org/10.1200/ JCO.2002.03.084

[6] O'SUllivan B, DAVIS AM, TURCOTTE R, BELL R, CATTON C et al. Preoperative versus postoperative radiotherapy in soft-tissue sarcoma of the limbs: a randomised trial. Lancet 2002; 359: 2235-2241. https://doi.org/10.1016/ S0140-6736(02)09292-9

[7] YANG JC, CHANG AE, BAKER AR, SINDELAR WF, DANFORTH DN et al. Randomized prospective study of the benefit of adjuvant radiation therapy in the treatment of soft tissue sarcomas of the extremity. J Clin Oncol 1998; 16: 197-203. https://doi.org/10.1200/JCO.1998.16.1.197

[8] NIELSEN OS, CUMMINGS B, O'SULLIVAN B, CATTON C, BELL RS et al. Preoperative and postoperative irradiation of soft tissue sarcomas: effect of radiation field size. Int J Radiat Oncol Biol Phys 1991; 21: 1595-1599. https://doi. org/10.1016/0360-3016(91)90337-4

[9] SADOSKI C, SUIT HD, ROSENBERG A, MANKIN H, EFIRD J. Preoperative radiation, surgical margins, and local control of extremity sarcomas of soft tissues. J Surg Oncol 1993; 52: 223-230. https://doi.org/10.1002/jso.2930520405
[10] WAMBERSIE A, DUTREIX A, PIERQUIN B, DARDENNE JC. [Foreseeable dosimetry in the interstitial therapy using Iridium 192 wires ("Paris system"). Applications in a single plane]. J Belge Radiol 1972; 55: 197-206.

[11] SOYFER V, CORN BW, KOLLENDER Y, TEMPELHOFF H, MELLER I et al. Radiation Therapy for Palliation of Sarcoma Metastases: A Unique and Uniform Hypofractionation Experience. Sarcoma 2010; 2010: 1-4. https://doi. org/10.1155/2010/927972

[12] U.S. DEPARTMENT OF HEALTH AND HUMAN SERVICES. Common Terminology Criteria for Adverse Events (CTCAE) Version 5.0. Published online November 27, 2017. https://ctep.cancer.gov/protocoldevelopment/electronic_applications/docs/CTCAE_v5_Quick_Reference_5x7.pdf

[13] COINDRE JM. Grading of soft tissue sarcomas: review and update. Arch Pathol Lab Med 2006; 130: 1448-1453. https:// doi.org/10.1043/1543-2165(2006)130[1448:GOSTSR]2.0. $\mathrm{CO} ; 2$

[14] PISTERS PW, HARRISON LB, LEUNG DH, WOODRUFF JM, CASPER ES et al. Long-term results of a prospective randomized trial of adjuvant brachytherapy in soft tissue sarcoma. J Clin Oncol 1996; 14: 859-868. https://doi.org/10.1200/ JCO.1996.14.3.859

[15] CORREA R, GÓMEZ-MILLÁN J, LOBATO M, FERNÁNDEZ A, ORDONEZZ R et al. Radiotherapy in soft-tissue sarcoma of the extremities. Clin Transl Oncol 2018; 20: 11271135. https://doi.org/10.1007/s12094-018-1848-x

[16] SAMPATH S, SCHULTHEISS TE, HITCHCOCK YJ, RANDALL RL, SHRIEVE DC et al. Preoperative Versus Postoperative Radiotherapy in Soft-Tissue Sarcoma: Multi-Institutional Analysis of 821 Patients. Int J Radiat Oncol 2011; 81: 498-505. https://doi.org/10.1016/j.ijrobp.2010.06.034

[17] MÜLLER DA, BELTRAMI G, SCOCCIANTI G, FRENOS F, CAPANNA R. Combining limb-sparing surgery with radiation therapy in high-grade soft tissue sarcoma of extremities - Is it effective? Eur J Surg Oncol 2016; 42: 1057-1063. https://doi.org/10.1016/j.ejso.2016.02.004

[18] PISTERS PW, LEUNG DH, WOODRUFF J, SHI W, BRENNAN MF. Analysis of prognostic factors in 1,041 patients with localized soft tissue sarcomas of the extremities. J Clin Oncol 1996; 14: 1679-1689. https://doi.org/10.1200/ JCO.1996.14.5.1679

[19] MANIR KS, BASU A, CHOUDHURY KB, BASU S, GHOSH $\mathrm{K}$ et al. Interstitial brachytherapy in soft tissue sarcoma: a 5 years institutional experience with Cobalt 60-based highdose-rate brachytherapy system. J Contemp Brachytherapy 2018; 10: 431-438. https://doi.org/10.5114/jcb.2018.78994

[20] NAGHAVI AO, FERNANDEZ DC, MESKO N, JULOORI A, MARTINEZ A et al. American Brachytherapy Society consensus statement for soft tissue sarcoma brachytherapy. Brachytherapy 2017; 16: 466-489. https://doi.org/10.1016/j. brachy.2017.02.004

[21] LAZZARO G, LAZZARI R, PELOSI G, DE PAS T, MARIANI L et al. Pulsed Dose-Rate Perioperative Interstitial Brachytherapy for Soft Tissue Sarcomas of the Extremities and Skeletal Muscles of the Trunk. Ann Surg Oncol 2005; 12: 935-942. https://doi.org/10.1245/ASO.2005.11.004 
[22] NESSELER JP, SALLERON J, RIOS M, NICKERS P, MARCHAL $\mathrm{F}$ et al. A retrospective cohort study to assess adjuvant concurrent chemoradiation (CCRT) compared to adjuvant radiation therapy (RT) in the treatment of grade 2 and 3 extremity soft tissue sarcomas. Radiother Oncol 2017; 125: 160-167. https://doi.org/10.1016/j.radonc.2017.08.037

[23] MUHIC A, HOVGAARD D, MØRK PETERSEN M, DAUGAARD S, HØJLUND BECH B et al. Local control and survival in patients with soft tissue sarcomas treated with limb sparing surgery in combination with interstitial brachytherapy and external radiation. Radiother Oncol 2008; 88: 382-387. https://doi.org/10.1016/j.radonc.2008.06.002

[24] CORTESI A, GALUPPI A, FRAKULli R, ARCELli A, ROMANI $\mathrm{F}$ et al. Adjuvant radiotherapy with brachytherapy boost in soft tissue sarcomas. J Contemp Brachytherapy 2017; 3: 256-262. https://doi.org/10.5114/jcb.2017.68215

[25] DAVIS AM, O'SULLIVAN B, TURCOTTE R, BELL R, CATTON $\mathrm{C}$ et al. Late radiation morbidity following randomization to preoperative versus postoperative radiotherapy in extremity soft tissue sarcoma. Radiother Oncol 2005; 75: 48-53. https://doi.org/10.1016/j.radonc.2004.12.020

[26] ALEKTIAR KM, BRENNAN MF, SINGER S. Local control comparison of adjuvant brachytherapy to intensitymodulated radiotherapy in primary high-grade sarcoma of the extremity. Cancer 2011; 117: 3229-3234. https://doi. org/10.1002/cncr.25882
[27] FOLKERT MR, CASEY DL, BERRY SL, CRAGO A, FABBRI N et al. Femoral Fracture in Primary Soft-Tissue Sarcoma of the Thigh and Groin Treated with Intensity-Modulated Radiation Therapy: Observed versus Expected Risk. Ann Surg Oncol 2019; 26: 1326-1331. https://doi.org/10.1245/ s10434-019-07182-5

[28] O'SULLIVAN B, GRIFFIN AM, DICKIE CI, SHARPE MB, CHUNG PWM et al. Phase 2 study of preoperative imageguided intensity-modulated radiation therapy to reduce wound and combined modality morbidities in lower extremity soft tissue sarcoma: Phase 2 IMRT Sarcoma Study. Cancer 2013; 119: 1878-1884. https://doi.org/10.1002/cncr.27951

[29] DI BRINA L, FOGLIATA A, NAVARRIA P, D'AGOSTINO G, FRANZESE $C$ et al. Adjuvant volumetric modulated arc therapy compared to $3 \mathrm{D}$ conformal radiation therapy for newly diagnosed soft tissue sarcoma of the extremities: outcome and toxicity evaluation. Br J Radiol 2019; 92: 20190252. https://doi.org/10.1259/bjr.20190252

[30] ORTIZ GONZÁLEZ I, MORERA CANO D, SÁNCHEZ RR, SALVADOR PM, BLANCO LV et al. Dosimetric comparison of volumetric-arc therapy versus sliding window intensity-modulated radiotherapy in postoperative treatment for primary soft tissue sarcoma of the thigh. Asia Pac J Clin Oncol 2019; 15: 371-376. https://doi.org/10.1111/ajco.13220 